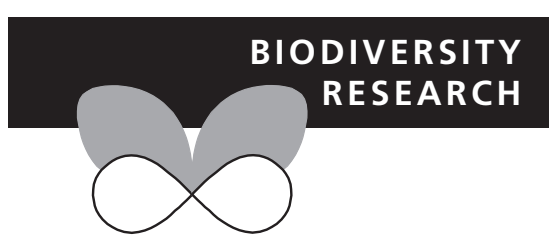

\title{
Predicting invasiveness of Australian acacias on the basis of their native climatic affinities, life history traits and human use
}

\author{
Pilar Castro-Díez ${ }^{1 \star}$, Oscar Godoy ${ }^{1,2,3}$, Asunción Saldaña ${ }^{1}$ \\ and David M. Richardson ${ }^{4}$
}

\begin{abstract}
${ }^{1}$ Departamento de Ecología, Universidad de Alcalá, Campus Universitario, Ctra. MadridBarcelona Km. 33.6, E-28871 Alcalá de Henares, Madrid, Spain, ${ }^{2}$ Laboratorio Internacional de Cambio Global MNCNCSIC, Serrano 115. E28006 Madrid, Spain, ${ }^{3}$ Department of Ecology, Evolution and Marine Biology, University of California, Santa Barbara, California 93106 USA, ${ }^{4}$ Centre for Invasion Biology, Department of Botany and Zoology, Stellenbosch University, Private Bag X1, Matieland 7602, South Africa
\end{abstract}

${ }^{*}$ Correspondence: Pilar Castro-Díez, Departamento de Ecología, Universidad de Alcalá, Campus Universitario, Ctra. MadridBarcelona Km. 33.6, E-28871 Alcalá de Henares, Madrid, Spain.

E-mail: mpilar.castro@uah.es

\begin{abstract}
Aim Many Australian Acacia species have been widely planted around the world. Some taxa are among the most aggressive of invasive alien plants and cause severe ecosystem degradation. We aimed to predict invasiveness of taxa in a large set of Australian Acacia species on the basis of easy-to-assess predictors.
\end{abstract}

Location Global.

Methods We considered three groups of predictors: (1) climatic affinities of species in their native ranges; (2) life history traits; and (3) human usage factors. Logistic multiple regressions were applied to construct predictive models for 85 Australian acacias (species in Acacia subgenus Phyllodineae) that are known to have been transported outside of their native range (17 known to be invasive and 68 non-invasive). The best model was then applied to predict the probability of an additional 34 Acacia species with unknown invasive status.

Results Water availability in the native range and human uses were significant predictors of invasiveness in all models. Life history index (proportional to plant height, leaf area and seed mass) and climatic amplitude were also positive predictors of invasiveness when human use was not considered. The best model, based on human uses and water availability, correctly classified $92 \%$ of the species. Results suggest that Acacia species that evolved under low climatic stress have a greater chance of becoming invasive.

Main conclusions Species that are useful to humans are more likely to be disseminated to and within new regions, thus increasing the risk of invasion. Combining ecological, evolutionary and human-use criteria is useful for quantifying the risk of Australian acacias becoming invasive. Acacia species can attain invasive status by virtue of intrinsic traits and/or through increased use by humans. Therefore, we predict that the invasion risk of species coming from native areas with high water availability will rise sharply if the interest in exploiting these species increases.

\section{Keywords}

Biological invasions, climatic amplitude, invasive species, life-history traits, native range, predictive models, risk assessment.

\section{INTRODUCTION}

Biological invasions cause substantial disruption to ecosystem functioning and drive biotic homogenization, loss of biodiversity, and reduced ecosystem services in many parts of the world (Olden \& Rooney, 2006; Vilà et al., 2010). Despite the successful eradication of some invasive alien species (Simberloff, 2009), the costs and likelihood of failure of eradication programmes rise dramatically when invasions are widespread (Hulme, 2006; Simberloff, 2009). Therefore, identifying the determinants of invasiveness is crucial for reducing the number of invasive species and their potential ecological impacts. 
Since Baker's attempt to identify the profile of the ideal weed' (Baker, 1965), the search for sets of traits or syndromes that predispose a species to become invasive has been a major aim in invasion ecology (Rejmánek \& Richardson, 1996; Richardson \& Pyšek, 2006; Van Kleunen \& Johnson, 2007; Van Kleunen et al., 2010). Studies conducted since the 1990s have shown that identifying traits that are consistently associated with invasiveness is difficult and frequently context-dependent (Alpert et al., 2000; Lloret et al., 2005; Dawson et al., 2009). Even so, the increasing availability of data, especially in the last decade, has prompted the publication of many multispecies studies which seek broad generalizations, (Pyšek \& Richardson, 2007; Van Kleunen et al., 2007, 2010; Dawson et al., 2009). These studies report contrasting results. For instance, plant height was reported to be higher in invasive alien than in native plants in some studies (Crawley et al., 1996; Williamson \& Fitter, 1996; Goodwin et al., 1999), while others found no relationship between invasiveness and plant height (Hamilton et al., 2005; Lloret et al., 2005; Cadotte et al., 2006a). Based on large datasets, Leishman et al. (2007) found invasive alien species to be positioned further towards the faster growth strategy than coexisting natives, while Daehler (2003) concluded that alien invaders were not more likely to have higher growth rates than coexisting natives. Seeds of invasive alien plants have been found to be bigger (Crawley et al., 1996), smaller (Rejmánek \& Richardson, 1996; Lake \& Leishman, 2004; Hamilton et al., 2005), or no different from natives or non-invasive aliens (Williamson \& Fitter, 1996; Lloret et al., 2005; Cadotte et al., 2006a). Successful invaders have been found to display earlier (Cadotte \& Lovett-Doust, 2001; Belmonte \& Vilà, 2004), later (Celesti-Grapow et al., 2003; Godoy et al., 2009a), longer (Lloret et al., 2005; Pyšek et al., 2009) or similar (Godoy et al., 2009b) flowering season compared to native species. The lack of clear differences in these studies is not surprising for several reasons. Firstly, given the wide variety of approaches, scales, invasion stages, evolutionary histories and biogeographical origins used in multispecies comparisons (Pyšek \& Richardson, 2007; Dawson et al., 2009; Godoy et al., 2009b), clear-cut differences would not be expected. Secondly, because different traits and syndromes confer markedly different advantages in different taxonomic groups and/or habitats (Crawley et al., 1996; Alpert et al., 2000; Lloret et al., 2005), meaningful, strong cross-taxon differences in traits could not explain invasiveness. Moreover, variation in residence time and human uses of alien species adds considerable biases to multispecies comparative studies (Thuiller et al., 2006; Van Kleunen et al., 2007; Wilson et al., 2007). A recent review combining the results of many studies in a single meta-analysis revealed that invasive species generally have higher values of performance-related traits (i.e. rates of physiological processes, resource use efficiencies, allocation to leaf area and shoot, growth rate, size and fitness) than noninvasive species (Van Kleunen et al., 2010). Although this finding was consistent under many circumstances, the effect size of the comparison depended on the climate of the study region, on whether the invasive alien species and non-invasive species had the same growth form, belonged to the same family, or whether the control species was a non-invasive alien or a native species (Van Kleunen et al., 2010).

One strategy to reduce the above variation is to focus on particular phylogenetic groups of species (Rejmánek \& Richardson, 1996; Richardson, 2006; Van Kleunen \& Johnson, 2007) or on alien species coming from and/or introduced to the same geographic region (Goodwin et al., 1999; Pyšek et al., 2004a; Cadotte et al., 2006b). Particularly, comparisons among congeneric or confamilial species, sometimes coming from the same region, have identified more traits explaining invasiveness than multispecies comparisons (Richardson, 2006; Pyšek \& Richardson, 2007; Van Kleunen et al., 2007). However, there are a few large plant phylogenetic groups which have been widely transported and disseminated in new areas and where accurate information can be obtained on the fate of such introductions. A study of the traits of a set of 24 Pinus species planted throughout the world and differing in invasiveness showed that a syndrome of life history traits clearly separated invasive from non-invasive species: small seeds, early age of first reproduction, and frequent large seed crop events (Richardson, 2006). A study of Iridaceae species native to South Africa and planted world-wide showed that rapid and profuse seedling emergence were key traits contributing to naturalization success (Van Kleunen et al., 2007), while climatic characteristics of the native region, human uses and life history traits were important for explaining their invasion success (Van Kleunen \& Johnson, 2007).

An obvious taxonomic group with strong potential in this regard is the genus Acacia (Fabaceae). This genus (sensu lato) encompasses over 1350 species, and most of them are native to Australia (Breton et al., 2008; Miller et al., 2011; Richardson et al., 2011). Australian acacias started to be widely planted outside of their natural range in the late 1700s because of their wide variety of uses (e.g. forestry, fodder, gardening, tannin production and sand dune binding) (Breton et al., 2008). Some of them are now major invasive species in many parts of the world (Weber, 2003; Richardson \& Rejmánek, 2011), for example, A. dealbata, A. melanoxylon, A. saligna and A. cyclops (Breton et al., 2008). Other acacias are rated as non-invasive (e.g. A. ampliceps, A. drummondii and A. microcarpa), while for others their status as introduced species is not clear, either because of contradictory reports or because of lack of reports on their invasiveness (e.g. A. aneura and A. floribunda) (cf. World Wide Wattle Dataset, http://www.worldwidewattle. $\mathrm{com} /$ ).

The aim of our study was to search for predictors of invasiveness among a set of 85 Australian Acacia species. By focusing on this genus, we avoid the variation associated with different species taxonomy and life history (all Acacia species are phanerophytes), and by focusing on acacias native to Australia, we reduce the variation associated with different species origins (Pyšek \& Richardson, 2007; Van Kleunen \& Johnson, 2007; Godoy et al., 2009b). By comparing the characteristics of invasive and non-invasive Acacia species from the same region, we focus our search on the characteristics that 
predispose species to become invasive, which is the relevant question to risk assessment. This type of study is much scarcer than comparisons of exotic invasive vs. native species (Pyšek \& Richardson, 2007; Van Kleunen et al., 2010), which provide insights into the traits that provide invasive aliens with advantage over native species (Hamilton et al., 2005).

We selected potential predictors of invasiveness that have been previously linked to invasive success in cross-species or congeneric comparisons (Goodwin et al., 1999; Alpert et al., 2000; Thuiller et al., 2006; Van Kleunen et al., 2010) and divided them into three categories: (1) climatic affinities of the species in their native range, (2) life history traits and (3) human use. Specifically, we aimed to assess the relative contribution of each predictor group by means of logistic multiple regression and to use the best model to predict the risk of invasion of those Acacia species whose invasive status is still unclear.

Invasive alien plants have been frequently reported to be fast growers, particularly when related invasive and non-invasive species are compared (Grotkopp et al., 2002; Burns, 2004; Grotkopp \& Rejmánek, 2007; Leishman et al., 2007; Zheng et al., 2009; Van Kleunen et al., 2010). Given that fast-growth genotypes are selected for in non-stressful environments (Grime, 1977, 1988), we expect invasive Acacia taxa to be native to regions with low climatic stress (hypothesis 1). Alternatively, invasive acacias may be those showing a wide climatic amplitude in their native range (hypothesis 2), because the same traits that allow a species to be widespread in the native range should contribute to their ability to overcome abiotic filters and successfully establish in a new region (Rejmánek, 1996; Goodwin et al., 1999; Booth et al., 2003). On the basis of previous literature (Crawley et al., 1996; Rejmánek \& Richardson, 1996; Goodwin et al., 1999; Lloret et al., 2005), we expect Acacia invasive species to be taller, to be able to regenerate vegetatively (resprout), to have smaller seeds, larger leaves, and a longer flowering season than noninvasive species (hypothesis 3). Finally, Acacia species useful for humans are more likely to be transported elsewhere and then they are expected to become invasive more often (hypothesis 4) (Alpert et al., 2000; Pyšek et al., 2003; Thuiller et al., 2006).

\section{METHODS}

\section{Species selection}

Among the set of Acacia species native to Australia, we selected those which have been transported elsewhere, on the basis of the International Legume Database and Information Service (ILDIS) (http://www.ildis.org/LegumeWeb/, version 10, November 2005). We checked in floras/checklists from all over the world (see Appendix S1 in Supporting information) to determine which species were considered to be 'invasive' and 'non-invasive' in particular countries. We classified as 'invasive' those Acacia species that were recorded as such (using the criteria of Pyšek et al. (2004b)) in at least two different sources of information from different countries (17 species). We chose this conservative criterion to avoid the possible inclusion of 'casual species' which can exhibit an explosive demographic growth during a few decades, but then die out. Non-invasive acacias were those that were not listed as invasive in any flora/ checklist (68 species). Finally, a subset of 34 Acacia species comprised those that were either considered as invasive in only one source, or where their status as aliens was not well-defined. The first two groups were used to construct models to predict invasiveness. These models were then applied to the third species set to predict the probability of these species becoming invasive.

\section{Data collection}

\section{Climatic information}

Distribution maps of every species were downloaded from Flora of Australia Online (http://www.environment.gov.au/ biodiversity/abrs/online-resources/flora/main/), from July to December 2008. When a species contained more than one distribution map for different subspecies/varieties, all their areas were lumped to define the distribution of the whole species. This is appropriate since many records of species outside the native range do not list subspecies/varieties or have questionable records of subspecific taxa. From the WorldClim database (Hijmans et al., 2009), we extracted for Australia several climatic variables accounting for annual mean trends and within-year variability: annual precipitation, precipitation seasonality (calculated as the coefficient of variation of precipitation throughout the year), maximum temperature of the warmest month and temperature seasonality (calculated as the standard deviation of temperature throughout the year). After checking that mean annual temperature was highly correlated with maximum temperature of the warmest month ( $R=0.88, P>>0.001)$, the latter was selected because of its normal distribution, which was a requisite for subsequent statistical analysis (see below). Distribution maps were geometrically corrected in ERDASC and overlaid with maps of climatic variables to obtain the mean, maximum and minimum values for each climatic variable through the distribution range of every species. The amplitude of each climatic variable was calculated by subtracting the minimum from the maximum value through the distribution range of every species. Table 1 shows the selected variables.

\section{Life history traits}

Mean plant height, leaf/phyllode dimensions (see below) and flowering length (number of months between the initial and the last month of flowering) were recorded from the World Wide Wattle site web (http://www.worldwidewattle.com/) at species level. This website compiles information from several sources of Australian national (including Flora of Australia) and regional flora information. Our first search was in Flora of Australia online. If no data were available there, we consulted 
Table 1 Summary of the variables included in the study as potential predictors of invasiveness in Australian Acacia species. Variables were grouped in four categories (shown in the first column). Climatic variables were extracted from the WorldClim database, life history traits from different floras, databases and/or consultation with experts, and the human-use index is the number of applied subjects in which the ISI Web of Knowledge classifies all publications on each species (see text).

\begin{tabular}{|c|c|c|c|}
\hline Variable type & Variable name & Abbreviation & Units \\
\hline \multirow[t]{4}{*}{ Range-average climatic variables } & Maximum temperature of warmest month & $T_{\max }$ & ${ }^{\circ} \mathrm{C}$ \\
\hline & Annual precipitation & $P_{\mathrm{ann}}$ & $\mathrm{mm}$ \\
\hline & Temperature seasonality $^{1}$ & $T_{\text {seas }}$ & ${ }^{\circ} \mathrm{C}$ \\
\hline & Precipitation seasonality ${ }^{2}$ & $P_{\text {seas }}$ & - \\
\hline \multirow[t]{4}{*}{ Range amplitude of climatic variables ${ }^{3}$} & Annual mean temperature range & $T_{\text {m.range }}$ & ${ }^{\circ} \mathrm{C}$ \\
\hline & Annual precipitation range & $P_{\text {ann.range }}$ & $\mathrm{mm}$ \\
\hline & Temperature seasonality range & $T_{\text {seas.range }}$ & ${ }^{\circ} \mathrm{C}$ \\
\hline & Precipitation seasonality range & $P_{\text {seas.range }}$ & - \\
\hline \multirow[t]{5}{*}{ Life history traits } & Mean plant height & $\mathrm{H}$ & $\mathrm{m}$ \\
\hline & Leaf/phyllode area & LA & $\mathrm{cm}^{2}$ \\
\hline & Flowering length & FL & months \\
\hline & Seed mass & SM & g \\
\hline & Resprouting ability & RA (binary) & - \\
\hline Human use & No. applied subjects on ISI Web of Knowledge & $\mathrm{HU}$ & - \\
\hline
\end{tabular}

${ }^{1}$ Standard deviation of temperature throughout the year.

${ }^{2}$ Coefficient of variation of precipitation throughout the year.

${ }^{3}$ Maximum minus minimum value of each variable through the native distribution range of the species.

regional floras (Floras of Western Australia, Queensland, Victoria and South Australia). Seed mass was recorded from the online Kew Garden seed database (http://data.kew.org/sid/ sidsearch.html, accessed in June 2009). When a range of values was reported for a species by the consulted source, we recorded the average of the range, excluding the extremes given in parentheses. When individual values were given for different subspecies/varieties within a species, they were averaged to get a single value at species level.

The area of phyllodes/pinnulae was calculated from their average length and width, using the formula of the ellipse area. When the species possessed compound leaves (normally bipinnate), the area was obtained after multiplying the pinnula area by the average number of pinnulae per leaf. In the few cases when phyllodes/pinnulae dimensions were not provided, we calculated their area from the Flora of Australia drawings, by using Sigma Scan Pro 5.0 software (SPSS Inc, Chicago, IL, USA). Resprouting ability of species was coded as a binary variable on the basis of information found in World Wide Wattle and consultation with experts (Bruce Maslin, author of Flora of Australia volumes $11 \mathrm{~A}$ and $11 \mathrm{~B}$, dedicated to Australian Acacia genera, and creator of the World Wide Wattle website, and Martin O'Leary, Acacia expert from the Plant Biodiversity Centre, Adelaide South Australia). Seed mass was unknown for 11 species (10 non-invasive and one with unclear status) and flowering length for 17 non-invasive species.

\section{Human use}

Previous studies have used the number of uses that a species has for humans as a measure of human-use intensity (Thuiller et al., 2006). We looked for this value in public databases, but found good information for only a small proportion of species on our list [seven species were found in The World Agroforestry Centre (http://www.worldagroforestrycentre.org/sea/) and 24 in The Germplasm Resources Information Network, GRIN Taxonomy Database (http://www.ars-grin.gov/cgi-bin/ npgs/html/econ.pl)]. We then consulted the World Wide Wattle dataset (http://www.worldwidewattle.com/), searched for every species and counted the number of uses described for each species; these were divided into five categories. Although this source contained information for more species $(n=92)$, it was not always clear whether a described use is a potential or an actual use. Finally, we consulted the ISI Web of Knowledge (Web of Science, http://www.isiknowledge.com), entered the name of every species in the field of 'topic' of the search form, and publication year from 1900 to 2009 (the search was conducted during September 2009). The resulting number of papers was recorded as an index of the species interest, and the number of applied scientific subjects in which those papers were included was considered as a proxy for 'number of human uses' both in the native and in the introduced ranges (see Appendix S2 for a list of Web of Science subjects considered as 'applied'). This last-mentioned source has several advantages: it is highly objective, it is updated every year, and it provides information for all species that have been studied. To assess the consistency of this index, we checked its correlation with the number of uses provided by the other consulted sources. The correlations were $r=0.93 P=0.003, r=0.82 P<0.001$ and $r=0.46 P<0.001$ for the 7, 24 and 92 species provided by the above-mentioned three sources, respectively. Given this consistent result, we decided to use the human-use index derived from ISI Web of Knowledge in analyses. 


\section{Statistical analysis}

We first explored differences of all metrics between invasive and non-invasive Acacia species using a Student's $t$-test, correcting for unequal variances when necessary, or MannWhitney $U$-test. For the binary trait 'resprouting ability', a chisquare test was conducted. Because of the high number of predicting variables and potential collinearity among them, we ran a principal component analysis (PCA) with all continuous variables to extract orthogonal axes explaining most of the matrix variance. Those variables that did not meet normality assumption were square-root or Ln-transformed. We first ran a PCA using the whole dataset, minus human use and resprouting ability, which have Poisson and binomial distributions, respectively. Then, we repeated the analysis, removing flowering length, because it had little contribution to the principal components (data not shown) and its inclusion necessitated the dropping of 17 species for which no data were available. Seed mass, also with 10 missing values, was kept because of its high weight in one of the components (see below). The final analysis was thus performed with 17 invasive species, 58 or 68 non-invasive (depending on whether seed mass-based predictors were included or not) and 34 non-clear status. For each main component of the PCA, we selected the variable(s) which better correlated with the component, to be used as invasiveness predictors in the subsequent analyses.

Different binomial multiple regression models (logit as link function) were constructed using invasiveness (binomial variable) as the independent variable and, as predictors, all possible combinations of the variables standing for the principal components, resprouting ability and human use. The Akaike Information Criterion index (AIC) was calculated to select the best model (Burnham \& Anderson, 2002), i.e. the one with the lowest AIC value. Two models are considered to be different if their AIC difference is higher than 2 (Burnham \& Anderson, 2002). The coefficients obtained for the best model (i.e. the one with the lowest AIC), and their 95\% confidence intervals, were used to calculate the probability of non-clear status acacias becoming invasive. The cut-off probability for considering a species invasive or non-invasive was 0.5. Statistical analyses were performed using SPSS 17.0 and R software version 2.8.0.

\section{RESULTS}

\section{Comparison of metrics between invasive and non-invasive species}

The native area of invasive Acacia species had on average lower $T_{\max }$ and $T_{\text {seas }}$, higher $P_{\text {ann }}$ and higher amplitude of both $T_{\mathrm{m}}$ and $P_{\text {ann }}$ than that of non-invasive ones (for full name of variables see Table 1). Invasive acacias were on average taller and had bigger leaves/phyllodes, had higher probability of being resprouters, and were used by humans for more purposes than non-invasive acacias. The other metrics did not differ between groups (Table 2).
Table 2 Mean \pm SE of climatic, life history and human-use metrics for invasive and non-invasive Australian Acacia species.

\begin{tabular}{lccr}
\hline Variable & Invasive & Non-invasive & $P$-value \\
\hline$T_{\text {max }}$ & $28.35 \pm 0.71$ & $31.21 \pm 0.55$ & 0.004 \\
$P_{\text {ann }}$ & $887.1 \pm 78.4$ & $588.2 \pm 41.3$ & $<0.001$ \\
$T_{\text {seas }}$ & $40.95 \pm 2.00$ & $49.44 \pm 0.83$ & 0.002 \\
$P_{\text {seas }}$ & $39.38 \pm 5.88$ & $36.43 \pm 2.21$ & 0.737 \\
$T_{\text {m.range }}$ & $13.45 \pm 1.05$ & $9.37 \pm 0.51$ & 0.001 \\
$P_{\text {ann.range }}$ & $2141 \pm 243$ & $1146 \pm 94$ & $<0.001^{2}$ \\
$T_{\text {seas.range }}$ & $28.40 \pm 2.06$ & $27.12 \pm 1.23$ & 0.2560 \\
$P_{\text {seas.range }}$ & $57.24 \pm 5.04$ & $57.48 \pm 3.97$ & 0.552 \\
H & $10.06 \pm 1.78$ & $4.04 \pm 0.48$ & $<0.001^{3}$ \\
LA & $25.93 \pm 5.97$ & $10.15 \pm 2.46$ & $0.002^{3}$ \\
FL & $4.82 \pm 0.45$ & $4.70 \pm 0.28$ & 0.946 \\
SD & $18.34 \pm 1.67$ & $29.29 \pm 5.84$ & 0.364 \\
RA & 52.94 & 20.59 & 0.007 \\
HU & $7.82 \pm 1.64$ & $0.76 \pm 0.27$ & $<0.001$ \\
\hline
\end{tabular}

${ }^{1}$ Significance after Chi-square test (RA), Mann-Whitney U-test (HU) or Student's t-test (remaining variables).

${ }^{2}$ Significance for square-root transformed data.

${ }^{3}$ Significance for Ln-transformed data.

${ }^{4} \mathrm{RA}$ represents the percentage of resprouting species in each group. $N=17$ for invasive species and $N=52,58$ or 68 non invasive species for FL, SM and the remaining variables, respectively. 58 Variable abbreviations as in Table 1.

\section{Data reduction}

The PCA performed on climatic and life history traits revealed that most of the variation was explained by climatic variables. The first principal component (PC1), explaining 34\% of the variance, was positively related to $P_{\text {ann }}$ and $P_{\text {ann.range }}$ and negatively to $T_{\max }$ and $T_{\text {seas. }}$. Therefore, PC1 can be interpreted as a measure of water availability (which increases with precipitation and decreases with temperature) and low thermal seasonality. The second principal component (PC2), accounting for $23 \%$ of variance, was a measure of thermal and seasonality range, being positively associated with $P_{\text {seas.range, }}$ $T_{\text {seas.range }}$ and, to a lesser extent, $T_{\text {m.range }}$ (Table 3 ). The third principal component (PC3), which explained 15\% of the variance, accounted for life history traits, with $\mathrm{H}$, LA and SM showing positive contributions (Table 3 ).

On the basis of the results and with the objective of not limiting the generality of our results for application to the assessment of invasiveness of other Acacia species in the future, we selected one predictor standing for each main component, consisting of the variable with the highest loading on the component, or a linear combination of the 2-3 variables with the highest loadings (using their scores on the main components, and keeping the transformations of the variables used in the PCA). The first one (Pred1), accounting for the first main component (water availability), was $0.91 \sqrt{P_{\text {ann }}}-0.84 T_{\max }$. The second predictor (Pred2), representing the second main component (climatic range) was $P_{\text {ann.range }}{ }^{0.3}$. The last predictor (Pred3) represented the third main component (life history traits) and was $0.64 \operatorname{Ln}(\mathrm{H})+0.66 \operatorname{Ln}(\mathrm{LA})+0.71 \sqrt{\operatorname{Ln}(\mathrm{SM})}$. The 
Table 3 Loadings of the variables on the three principal components extracted by the principal component analysis (PCA). FL was excluded from the analysis because it did not explain significant variation and its inclusion forced the elimination of 17 species.

\begin{tabular}{lccc}
\hline & PC1 & PC2 & PC3 \\
\hline$T_{\text {max }}$ & $-0.84^{*}$ & 0.30 & 0.29 \\
$P_{\text {ann }}$ & $0.91^{*}$ & -0.12 & 0.06 \\
$T_{\text {seas }}$ & $-0.69^{*}$ & -0.08 & 0.16 \\
$P_{\text {seas }}$ & -0.38 & 0.46 & 0.19 \\
$T_{\text {m.range }}$ & 0.54 & 0.57 & -0.07 \\
$P_{\text {ann.range }}$ & $0.80^{*}$ & 0.45 & -0.10 \\
$T_{\text {seas.range }}$ & -0.09 & $0.84^{*}$ & -0.33 \\
$P_{\text {seas.range }}$ & -0.26 & $0.90^{*}$ & -0.09 \\
H & 0.53 & 0.20 & $0.64^{*}$ \\
LA & 0.43 & 0.12 & $0.66^{*}$ \\
SM & -0.28 & 0.12 & $0.71^{*}$ \\
\hline
\end{tabular}

${ }^{*}$ Variables with the highest contribution to each PCA axis. Abbreviations as in Table 1 .

correlation coefficient between these predictors and each corresponding main component were $R=0.94,0.92$ and 0.79 , respectively $(P<0.001$ in all cases).

\section{Regression models}

Thirty-one binomial regression models were constructed with the dataset, to cover for all possible combinations of the five selected predictors (Pred1, Pred2, Pred3, RA and HU) (see Table 4). For most models, the reduction in unexplained deviance (measured as -2log-likelihood) after the inclusion of the predicting variables was highly significant (see chi-square and its significance in Table 4). Models including human use as predictor explained more deviance, showed lower AIC and correctly classified a higher proportion of species (over 90\%) than models not including this predictor (Table 4). Pred1 (water availability) and human use were positive and significant predictors of invasiveness in all models (Table 4). Pred2 (climatic range), Pred3 (life history traits) and resprout ability also contributed positively to invasiveness in some models (they were significant in 2, 7 and 4 of 16 models, respectively), but their contribution disappeared when human use was included as predictor (Table 4). On the basis of AIC, the best model was the first shown in Table 4, which only included Pred1 (water availability) and human use as predictors (Table S1). However, this model was not significantly different to models 2,3 and $4(\Delta \mathrm{AIC}<2)$ (Burnham \& Anderson, 2002).

The regression coefficients obtained in the best model (Model 1 of Table 4) were used for calculating the probability of each species being invasive (Fig. 1, Table 5 and Table S2). Among the 85 species with known invasive status, 92\% were correctly classified by model 1 . This model predicted six false negatives (invasive species whose predicted probability was lower than $50 \%$ ) and one false positive (non-invasive species whose predicted probability was higher than $50 \%$, see Fig. 1). Predicted probabilities for non-clear status Acacia species are shown in Table 5. Among them, only two species (A. holosericea and $A$. howittii) showed a probability of being invasive over 50\%. A. floribunda, A. terminalis, A. binervata and A. aneura showed probabilities between $34 \%$ and $50 \%$. The remaining species have probabilities lower than $26 \%$ (Table 5). The risk of $A$. holosericea and A. aneura being invasive is accounted for by their high scores of human-use index, while in the case of A. howittii, A. floribunda, A. terminalis and A. binervata, this risk is due to high scores for water availability in the native region (Pred1) (Fig. 2).

\section{DISCUSSION}

Predicting which species are predisposed to become invasive on the basis of their traits has been a research priority in invasion biology, as such knowledge can inform early detection, rapid response efforts (Hulme, 2006). These predictions are particularly relevant to species groups such as Australian acacias, given their high ecological and economic impact world-wide (Weber, 2003; Le Maitre et al., 2011; Wilson et al. 2011). This species group also has an obvious potential for conducting predictive studies, because of the high number of species common to a source region and the varying invasive success reported among them.

Among the variables used to predict Acacia invasiveness, water availability in the native range (Pred1) significantly and positively contributed to the likelihood of an Acacia species being invasive in all models (Table 4). This finding supports the idea that the most invasive Acacia species evolved under conditions of relatively low climatic stress (hypothesis 1), because such conditions select for fast-growth genotypes (Grime, 1977), a feature frequently associated with invasiveness (Grotkopp et al., 2002; Grotkopp \& Rejmánek, 2007; Leishman et al., 2007; Zheng et al., 2009). This is consistent with the higher height and leaf area found in invasive acacias as compared with non-invasive ones (Table 2), as these traits are typically found in mesic environments (Grime, 1977; Mooney et al., 1978; Werger \& Ellenbroek, 1978; Floret et al., 1990).

The niche amplitude of a species has for long been considered an important predictor of invasiveness; species with wide niches are more likely to (1) be pre-adapted to a range of conditions in any new area (Rejmánek, 1996; Goodwin et al., 1999; Booth et al., 2003) and (2) come into contact with humans and be carried elsewhere by international transport (Goodwin et al., 1999; Alpert et al., 2000). The expected wider climatic range for invasive acacias (hypothesis 2) was only partially supported by our results. Although mean temperature and annual precipitation ranges were significantly larger for invasive acacias (Table 2), climatic range (Pred2) was the least useful of the selected predictors of invasiveness in all models (Table 4). The latter result can be partly explained by the high contribution of water availability in the native range to invasiveness, as those species spanning over wide climatic ranges will exhibit lower scores for water availability than 
Table 4 Summary statistics of the binomial regression models using all possible combinations of the five selected predictors of invasiveness in Australian Acacia species. The partial regression coefficients are shown for each predicting variable in each model. Pred1 (water availability) $=0.91 \sqrt{P_{a n n}}-0.84 \mathrm{~T}_{\max }$, Pred2 (climatic amplitude $=P_{\text {ann.range }}{ }^{0.3}$, Pred3 (life history traits) $=0.64 \mathrm{Ln}(\mathrm{H})+0.66 \mathrm{Ln}(\mathrm{LA})+$ $0.71 \sqrt{\mathrm{Ln}(\mathrm{SM})}$. Abbreviations as in Table 1 . The null model correctly classified $77.3 \%$ or $80 \%$ of the cases for models including or excluding Pred3, respectively. A value of difference in AIC ( $\triangle \mathrm{AIC}$ ) higher than 10 represents a poorly fitted model compared to the best model, whereas a value of $<2$ indicates that both models are equivalent.

\begin{tabular}{|c|c|c|c|c|c|c|c|c|c|c|c|c|c|}
\hline Model & $\mathrm{df}$ & Intercept & Pred1 & Pred2 & Pred3 & RA & $\mathrm{HU}$ & $\begin{array}{l}\text { Residual } \\
\text { deviance }\end{array}$ & $\begin{array}{l}\text { Nagel- } \\
\text { Kerke } R^{2}\end{array}$ & $\begin{array}{l}\text { Chi- } \\
\text { square }\end{array}$ & $\begin{array}{l}\text { \% Cases } \\
\text { correctly } \\
\text { classified }\end{array}$ & AIC & $\triangle \mathrm{AIC}$ \\
\hline 1 & 82 & $-2.913^{* * *}$ & $0.189^{*}$ & & & & $0.614^{* * *}$ & 39.87 & 0.652 & $45.2^{* * *}$ & 91.8 & 45.87 & \\
\hline 2 & 71 & $-2.521^{\star}$ & $0.189^{\star}$ & & -0.094 & & $0.613^{* *}$ & 38.83 & 0.646 & $41.5^{\star \star \star}$ & 90.7 & 46.83 & 0.96 \\
\hline 3 & 81 & -5.021 & $0.202^{* \star}$ & 0.667 & & & $0.587^{\star *}$ & 39.50 & 0.656 & $45.6^{* * \star}$ & 91.8 & 47.50 & 1.63 \\
\hline 4 & 81 & $-2.902^{\star * *}$ & $0.189^{\star}$ & & & -0.076 & $0.619^{* *}$ & 39.86 & 0.652 & $45.2^{\star \star \star}$ & 91.8 & 47.86 & 1.99 \\
\hline 5 & 70 & -4.236 & $0.195^{*}$ & 0.500 & -0.045 & & $0.581^{* *}$ & 38.64 & 0.648 & $41.6^{* * *}$ & 90.7 & 48.64 & 2.77 \\
\hline 6 & 70 & $-2.532^{\star}$ & $0.188^{*}$ & & -0.084 & -0.075 & $0.615^{* *}$ & 38.82 & 0.646 & $41.5^{* * *}$ & 90.7 & 48.82 & 2.95 \\
\hline 7 & 80 & -5.153 & $0.204^{*}$ & 0.718 & & -0.215 & $0.599^{* *}$ & 39.46 & 0.657 & $45.6^{* \star \star}$ & 91.8 & 49.46 & 3.59 \\
\hline 8 & 69 & -4.623 & $0.195^{*}$ & 0.600 & -0.003 & -0.258 & $0.582^{* *}$ & 38.59 & 0.649 & $41.7^{* * *}$ & 90.7 & 50.59 & 4.72 \\
\hline 9 & 72 & $-3.271^{* *}$ & & & 0.247 & & $0.469^{* *}$ & 46.90 & 0.547 & $33.4^{* * *}$ & 92.0 & 52.90 & 7.03 \\
\hline 10 & 83 & $-2.743^{* * *}$ & & & & & $0.558^{* * *}$ & 49.07 & 0.543 & $36.0^{* * *}$ & 91.8 & 53.07 & 7.20 \\
\hline 11 & 71 & -1.150 & & -0.637 & 0.215 & & $0.502^{\star \star}$ & 46.42 & 0.553 & $33.9^{* * *}$ & 92.0 & 54.42 & 8.55 \\
\hline 12 & 71 & $-3.324^{* *}$ & & & 0.295 & -0.383 & $0.485^{\star *}$ & 46.72 & 0.549 & $33.6^{* * *}$ & 90.7 & 54.72 & 8.85 \\
\hline 13 & 82 & -1.145 & & -0.506 & & & $0.579^{* * *}$ & 48.73 & 0.505 & $33.3^{* * *}$ & 91.8 & 54.73 & 8.86 \\
\hline 14 & 82 & $-2.747^{\star * *}$ & & & & 0.020 & $0.556^{\star *}$ & 49.07 & 0.546 & $36.0^{* * *}$ & 91.8 & 55.07 & 9.20 \\
\hline 15 & 70 & -1.359 & & -0.583 & 0.248 & -0.257 & $0.510^{\star *}$ & 46.34 & 0.554 & $33.9^{* * *}$ & 92.0 & 56.34 & 10.47 \\
\hline 16 & 81 & -1.114 & & -0.522 & & 0.103 & $0.572^{\star * *}$ & 48.72 & 0.550 & $36.4^{\star * *}$ & 90.6 & 56.72 & 10.85 \\
\hline 17 & 71 & $-10.819^{* *}$ & $0.170^{\star *}$ & $2.186^{\star}$ & $0.682^{* *}$ & & & 53.89 & 0.451 & $26.4^{\star * \star}$ & 85.3 & 61.89 & 16.02 \\
\hline 18 & 70 & $-10.334^{\star *}$ & $0.170^{\star \star}$ & 2.063 & $0.625^{\star}$ & 0.330 & & 53.73 & 0.454 & $26.6^{* * *}$ & 86.7 & 63.73 & 17.86 \\
\hline 19 & 72 & $-3.789^{* * *}$ & $0.100^{\star}$ & & $0.734^{*}$ & & & 58.96 & 0.377 & $21.3^{* * *}$ & 82.7 & 64.96 & 19.09 \\
\hline 20 & 71 & $-3.619^{* *}$ & $0.112^{*}$ & & 0.600 & 0.749 & & 57.93 & 0.392 & $22.4^{\star * \star}$ & 85.3 & 65.93 & 20.06 \\
\hline 21 & 73 & $-4.533^{* * *}$ & & & $0.939^{* * *}$ & & & 63.81 & 0.300 & $16.5^{* * *}$ & 82.7 & 67.81 & 21.94 \\
\hline 22 & 81 & $-7.842^{\star}$ & $0.199^{* * *}$ & 1.823 & & $1.354^{*}$ & & 60.15 & 0.402 & $24.9^{* * *}$ & 85.9 & 68.15 & 22.28 \\
\hline 23 & 72 & $-5.949^{\star}$ & & 0.429 & $0.939^{* * *}$ & & & 63.45 & 0.306 & $16.8^{* \star}$ & 81.3 & 69.45 & 23.58 \\
\hline 24 & 72 & $-4.497^{\star * *}$ & & & $0.887^{\star \star}$ & 0.362 & & 63.51 & 0.305 & $16.8^{\star \star \star}$ & 82.7 & 69.51 & 23.64 \\
\hline 25 & 82 & $-8.732^{\star *}$ & $0.207^{* * *}$ & $2.241^{\star}$ & & & & 64.08 & 0.346 & $21.0^{* * *}$ & 80.0 & 70.08 & 24.21 \\
\hline 26 & 82 & $-1.999^{* * *}$ & $0.160^{\star \star}$ & & & $1.630^{*}$ & & 64.25 & 0.343 & $20.8^{\star \star \star}$ & 85.9 & 70.25 & 24.38 \\
\hline 27 & 71 & $-5.657^{\star}$ & & 0.350 & $0.898^{* *}$ & 0.278 & & 63.29 & 0.309 & $17.0^{* \star}$ & 82.7 & 71.29 & 25.42 \\
\hline 28 & 83 & $-1.429^{* * *}$ & $0.157^{\star \star}$ & & & & & 70.73 & 0.246 & $14.3^{* * *}$ & 82.4 & 74.73 & 28.86 \\
\hline 29 & 83 & $-1.909^{* * *}$ & & & & $1.468^{*}$ & & 78.47 & 0.118 & $6.6^{*}$ & 80.0 & 82.47 & 36.60 \\
\hline 30 & 82 & -2.763 & & 0.266 & & $1.422^{*}$ & & 78.30 & 0.121 & $6.8^{*}$ & 80.0 & 84.30 & 38.43 \\
\hline 31 & 83 & -3.143 & & 0.537 & & & & 84.30 & 0.014 & $0.8 \mathrm{~ns}$ & 80.0 & 88.30 & 42.43 \\
\hline
\end{tabular}

${ }^{* * *} P \leq 0.001,{ }^{* *} 0.001<P \leq 0.01,{ }^{*} 0.01<P \leq 0.05$, ns $0.05<P$.

species restricted to mesic regions. The fact that the regression coefficient of climatic range drops upon inclusion of human use in the models (Table 4) suggests that the chances of a species being selected by humans and transported elsewhere depends more on the uses of the species than on the niche amplitude.

Invasive acacias were on average taller, had larger leaves/ phyllodes and were more likely to resprout (also see Gibson et al., 2011) than non-invasive ones (Table 2), partially supporting our hypothesis 3. However, seed mass was not smaller in invasive acacias, as expected, and even has a positive contribution to invasiveness, as part of the life history predictor (Table 4). This result contrasts with findings for Pinus species (Rejmánek \& Richardson, 1996; Richardson,
2006), where small seed size was strongly linked to the invasive potential. This is not surprising, since the role of seed size in the overall reproductive syndrome differs radically between groups of plants. For pines, most of which are wind dispersed, seed size (together with wing dimensions) is a crucial mediator of the capacity for long-distance dispersal which is a major ingredient of invasive success in the group (Higgins \& Richardson, 1999). Dispersal by wind is not an important mode of expansion in acacias, and the role of seed size in mediating invasiveness is very different (Richardson \& Kluge, 2008; Gibson et al., 2011). In spite of the variety of habitats and succession stages invaded by acacias [c.f. Global Invasive Species Dataset (http://www.issg.org/database)], the life history predictor (Pred3) showed a significant and positive 


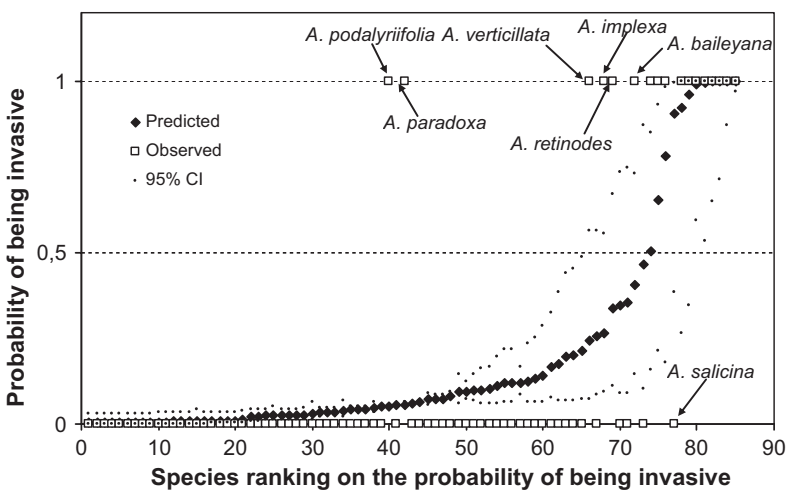

Figure 1 Observed (open squares: 0 , non-invasive; 1 , invasive) and predicted (filled diamonds) probability of being invasive on the basis of model 1 shown in Table 4. Small dots show the 95\% confidence interval for each estimated probability. $X$-axis shows the ranking of the species on the basis of their invasiveness probability. The names of the species are only shown for those with discrepancy between observed and predicted values (i.e. invasive species with predicted probabilities $<0.5$-upper part of the graph- and non-invasive species with predicted probability $>0.5$-lower part of the graph-). Predicted values for all species are reported in Supporting information Table S2.

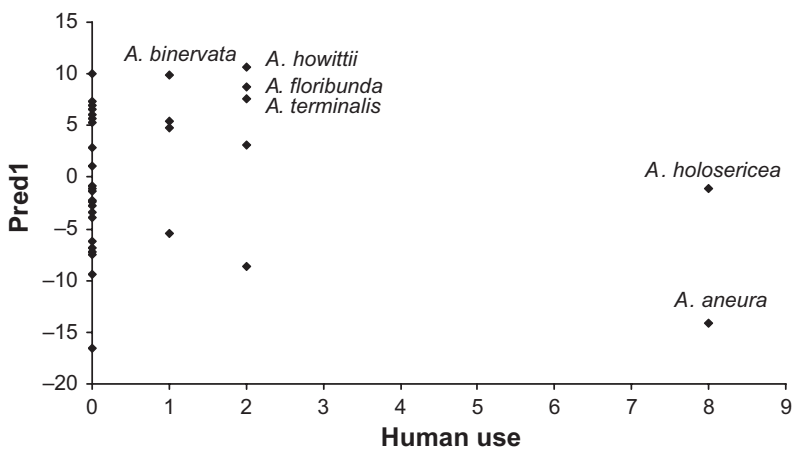

Figure 2 Scores of non-clearly classified Acacia species for the two invasiveness predictors included in Model 1 (see Table 4). Pred1 (water availability) $=0.91 \sqrt{P}_{\mathrm{ann}}-0.84 T_{\text {max }}$. The names of species with a probability of being invasive over $34 \%$ (on the basis of model 1) are shown.

contribution to invasiveness in seven of the eight models where human use was not included (Table 4). By summing up the values of three life history traits (plant height, leaf area and seed mass), the life history predictor may account for the different traits that contribute to invasive success in different contexts. For instance, large seed mass may contribute to establish in forested lands and/or stressful habitats (Burke \& Grime, 1996; Dawson et al., 2009), large leaf area may help to succeed under low-light environments (Niinemets \& Kull, 1994; Ackerly et al., 2002) and large plant height may be a key factor to succeed in regions lacking of native trees (Mack, 2003). However, the predictive value of both Pred 3 and resprout ability were overrode by human use, whose inclusion makes their significance disappear (Table 4).
Table 5 Probability of being invasive (P) calculated for the 34 Australian Acacia species with poorly defined invasive status, on the basis of model 1. 95\% confidence intervals (CI) are shown in parentheses. Species are ordered from higher to lower probability.

\begin{tabular}{ll}
\hline Acacia species & $P(95 \% \mathrm{CI})$ \\
\hline A. holosericea & $0.856(0.282,0.989)$ \\
A. howittii & $0.584(0.123,0.934)$ \\
A. floribunda & $0.494(0.114,0.881)$ \\
A. terminalis & $0.440(0.110,0.834)$ \\
A. binervata & $0.393(0.095,0.800)$ \\
A. aneura & $0.336(0.187,0.527)$ \\
A. boormanii & $0.265(0.076,0.614)$ \\
A. penninervis & $0.250(0.093,0.521)$ \\
A. parramattensis & $0.219(0.080,0.473)$ \\
A. myrtifolia & $0.197(0.078,0.416)$ \\
A. stricta & $0.179(0.068,0.393)$ \\
A. rubida & $0.169(0.067,0.365)$ \\
A. adunca & $0.159(0.066,0.335)$ \\
A. maidenii & $0.147(0.065,0.299)$ \\
A. fimbriata & $0.136(0.064,0.265)$ \\
A. oxycedrus & $0.128(0.063,0.241)$ \\
A. viscidula & $0.085(0.057,0.124)$ \\
A. buxifolia & $0.063(0.054,0.074)$ \\
A. neriifolia & $0.045(0.040,0.050)$ \\
A. gladiiformis & $0.042(0.036,0.049)$ \\
A. decora & $0.040(0.033,0.049)$ \\
A. microbotrya & $0.035(0.021,0.060)$ \\
A. pendula & $0.034(0.022,0.053)$ \\
A. cultriformis & $0.034(0.025,0.047)$ \\
A. acinacea & $0.034(0.024,0.047)$ \\
A. doratoxylon & $0.031(0.021,0.046)$ \\
A. glandulicarpa & $0.028(0.017,0.045)$ \\
A. cardiophylla & $0.025(0.014,0.044)$ \\
A. omalophylla & $0.017(0.007,0.040)$ \\
A. brachybotrya & $0.015(0.005,0.040)$ \\
A. notabilis & $0.014(0.005,0.039)$ \\
A. calamifolia & $0.013(0.004,0.038)$ \\
A. continua & $0.009(0.002,0.036)$ \\
A. craspedocarpa & $0.002(0.000,0.027)$ \\
\hline &
\end{tabular}

Acacia species useful for humans were expected to be more invasive because they have better chances of being transported and because of increasing propagule pressure (Alpert et al., 2000; Pyšek et al., 2003; Thuiller et al., 2006; Van Kleunen et al., 2007) (hypothesis 4). This hypothesis was supported by our results, as the inclusion of human use as predicting variable in the logistic models overrode the importance of other predictors (Table 4). Other studies performed on different sets of species and different regions consistently support the notion that species utilized by humans have an increased chance of becoming established outside the native region (Pyšek et al., 2003; Thuiller et al., 2006; Van Kleunen et al., 2007).

Our models suggest that an Acacia species can attain invasive status by having high scores for certain environmental or intrinsic traits (such as having evolved in mesic 
regions and possessing certain life history traits, e.g. A. verticilata and A. elata), and/or as a consequence of an intense human use (e.g. A. saligna). Predictions by model 1 are particularly accurate for species showing correlative values for the two main predictors, but uncertainty increases when one of the scores is high and the other is low. Regarding the only non-invasive species which our model classified as invasive (A. salicina, see Fig. 1), we should note that during the final revision of this paper we found evidence that this species is invasive in Israel (http://biogeography.free.fr/ invasive_plants/acacia_salicina.html). This provides additional support for the model. Finally, we must accept that our model fails to correctly classify a few particular invasive species (see Fig. 1), whose invasive success is mediated by factors not included in this study, such as the ability to establish symbiotic associations (Vitousek \& Walker, 1989) or the possession of particular allelochemicals (Inderjit et al., 2008), which can be relevant to different stages of the invasive process.

The set of 34 Acacia species with non-clear invasive status do not represent a major threat of invasion [ $72 \%$ of the species have a probability of being invasive lower than $20 \%$, and only two showed a probability over 50\% (A. holosericea and A. howotii), although both probabilities exhibited wide confidence intervals, see Table 5]. However, we should be cautious, not only about those species with high scores for human use (A. holosericea, A. aneura), but also about mesic species (A. howittii, A. binervata) or even those with high values of the life history predictor (A. parramattensis, A. terminalis, A. maidenii), as we can predict that their invasive potential will rise sharply should interest in exploiting these species increase. This is probably the case for A. salicina in Israel, as discussed above.

\section{CONCLUSIONS}

Comparing invasive and non-invasive species from the same native range (Australia) and taxonomic group (Acacia subgenus Phyllodinae) has proved useful for identifying species which could become invasive when introduced to a new region. These studies are particularly relevant to species groups that have important ecological effects on natural ecosystems and are economically important (Le Maitre et al., 2011). Water availability in the native region and number of human uses were found to be the best predictors of Australian Acacia invasiveness. This study also highlights that intrinsic properties, linked to particular climatic conditions and extrinsic factors (human use), interact to enable a species to overcome potential barriers to becoming invasive.

\section{ACKNOWLEDGEMENTS}

This study was supported by the grants CGL2007-61873/BOS, CGL2010-16388/BOS of the Spanish Ministry of Science and Innovation, POII10-0179-4700 of Junta de Comunidades de
Castilla-La Mancha and the REMEDINAL-2 network S2009/ AMB-1783 (Comunidad de Madrid). We are indebted to Martin O'Leary and Bruce Maslin for providing data on resprouting capacity. OG was supported by a fellowship from the Spanish Ministry of Science and Innovation. DMR acknowledges financial support from the DST-NRF Centre of Excellence for Invasion Biology and the Working for Water programme through their collaborative project on "Research for Integrated Management of Invasive Alien Species", Stellenbosch University, the Oppenheimer Memorial Trust and the Hans Sigrist Foundation.

\section{REFERENCES}

Ackerly, D.D., Knight, C.A., Weiss, S.B., Barton, K. \& Starnemer, K.P. (2002) Leaf size, specific leaf area and microhabitat distribution of chaparral woody plants: contrasting patterns in species level and community analysis. Oecologia, 130, 449-457.

Alpert, P., Bone, E. \& Holzapfel, C. (2000) Invasiveness, invasibility and the role of environmental stress in the spread of non-native plants. Perspectives in Plant Ecology, Evolution and Systematics, 3, 52-66.

Baker, H.G. (1965) Characteristics and modes of origin of weeds. The genetics of colonizing species (ed. by H.G. Baker and G.L. Stebbins), pp. 147-172, Academic Press, New York.

Belmonte, J. \& Vilà, M. (2004) Atmospheric invasion of nonnative pollen in the Mediterranean region. American Journal of Botany, 91, 1243-1250.

Booth, B.D., Murphy, S.D. \& Swanton, C.J. (2003) Weed ecology in natural and agricultural systems. CABI, Wallingford.

Breton, C., Guerin, J., Ducatillion, C., Medail, F., Kull, C.A. \& Berville, A. (2008) Taming the wild and 'wilding' the tame: Tree breeding and dispersal in Australia and the Mediterranean. Plant Science, 175, 197-205.

Burke, M.J.W. \& Grime, J.P. (1996) An experimental study of plant community invasibility. Ecology, 77, 776-790.

Burnham, K.P. \& Anderson, D.R. (2002) Model selection and multimodel inference. Springer, New York.

Burns, J.H. (2004) A comparison of invasive and non-invasive dayflowers (Commelinaceae) across experimental nutrient and water gradients. Diversity and Distributions, 10, 387-397.

Cadotte, M.W. \& Lovett-Doust, J. (2001) Ecological and taxonomic differences between native and introduced plants of southwestern Ontario. Ecoscience, 8, 230-238.

Cadotte, M.W., Murray, B.R. \& Lovett-Doust, J. (2006a) Ecological patterns and biological invasions: using regional species inventories in macroecology. Biological Invasions, 8, 809-821.

Cadotte, M.W., Murray, B.R. \& Lovett-Doust, J. (2006b) Evolutionary and ecological influences of plant invader success in the flora of Ontario. Ecoscience, 13, 388395.

Celesti-Grapow, L., Di Marzio, P. \& Blasi, C. (2003) Temporal niche separation of the alien flora of Rome. Plant invasions: 
ecological threats and management solutions (ed. by Child, L., Brock, J.H., Brundu, G., Prach, K., Pyšek, P., Wade, P.M. \& Williamson, M.), pp. 101-111, Backhuys, Leiden.

Crawley, M.J., Harvey, P.H. \& Purvis, A. (1996) Comparative ecology of the native and alien floras of the British Isles. Philosophical Transactions of the Royal Society of London B, 351, 1251-1259.

Daehler, C.C. (2003) Performance comparisons of co-occurring native and alien invasive plants: implications for conservation and restoration. Annual Review of Ecology Evolution and Systematics, 34, 183-211.

Dawson, W., Burslem, D. \& Hulme, P.E. (2009) Factors explaining alien plant invasion success in a tropical ecosystem differ at each stage of invasion. Journal of Ecology, 97, 657-665.

Floret, C., Galan, M.J., LeFloc'h, E., Orshan, E. \& Romane, F. (1990) Growth forms and phenomorphology traits along an environmental gradient: tools for studying vegetation? Journal of Vegetation Science, 1, 71-80.

Gibson, M., Richardson, D.M., Marchante, E., Marchante, H., Rodger, J.G., Stone, G.N., Byrne, M., Fuentes-Ramírez, A., George, N., Harris, C., Johnson, S.D., Le Roux, J.J., Murphy, D.J., Pauw, A., Prescott, M.N., Wandrag, E.M. \& Wilson, J.R.U. (2011) Reproductive biology of Australian acacias: fundamental mediator of invasive success? Diversity and Distributions, 17, 911-933.

Godoy, O., Castro-Díez, P., Valladares, F. \& Costa-Tenorio, M. (2009a) Different flowering phenology of alien invasive species in Spain: evidence for the use of an empty temporal niche? Plant Biology, 11, 803-811.

Godoy, O., Richardson, D.M., Valladares, F. \& Castro-Díez, P. (2009b) Flowering phenology of invasive alien plant species compared with native species in three Mediterranean-type ecosystems. Annals of Botany, 103, 485-494.

Goodwin, B.J., McAllister, A.J. \& Fahrig, L. (1999) Predicting invasiveness of plant species based on biological information. Conservation Biology, 13, 422-426.

Grime, J.P. (1977) Evidence for the existence of three primary strategies in plants and its relevance to ecological and evolutionary theory. American Naturalist, 111, 11691194.

Grime, J.P. (1988) The CRS model of primary plant strategies: origins, implications, and tests. Plant evolutionary biology (ed. by L.D. Gottlieb and S.K. Jain), pp. 371-393, Chapman and Hall, London.

Grotkopp, E. \& Rejmánek, M. (2007) High seedling relative growth rate and specific leaf area are traits of invasive species: phylogenetically independent contrasts of woody angiosperms. American Journal of Botany, 94, 526-532.

Grotkopp, E., Rejmánek, M. \& Rost, T.L. (2002) Toward a causal explanation of plant invasiveness: seedling growth and life-history strategies of 29 pine (Pinus) species. American Naturalist, 159, 396-419.

Hamilton, M.A., Murray, B.R., Cadotte, M.W., Hose, G.C., Baker, A.C., Harris, C.J. \& Licari, D. (2005) Life-history correlates of plant invasiveness at regional and continental scales. Ecology Letters, 8, 1066-1074.

Higgins, S.I. \& Richardson, D.M. (1999) Predicting plant migration rates in a changing world: the role of long-distance dispersal. American Naturalist, 153, 464-475.

Hijmans, R.J., Cameron, S., Parra, J., Jones, P., Jarvis, A. \& Richardson, K. (2009) WorldClim. Global climate data. Versión 1.4 (release 3). http://www.worldclim.org/ (accessed July 2008).

Hulme, P.E. (2006) Beyond control: wider implications for the management of biological invasions. Journal of Applied Ecology, 43, 835-847.

Inderjit, Seastedt, T.R., Callaway, R.M., Pollock, J.L. \& Kaur, J. (2008) Allelopathy and plant invasions: traditional, congeneric, and bio-geographical approaches. Biological Invasions, 10, 875-890.

Lake, J.C. \& Leishman, M.R. (2004) Invasion success of exotic plants in natural ecosystems: the role of disturbance, plant attributes and freedom from herbivores. Biological Conservation, 117, 215-226.

Le Maitre, D.C., Sheppard, A.W., Marchante, E., Holmes, P., Gaertner, M., Rogers, A., Pauchard, A., Ens, E.J., González Rodríguez, L. \& Richardson, D.M. (2011) Impacts of Australian acacias: implications for management and restoration. Diversity and Distributions, 17, 1015-1029.

Leishman, M.R., Haslehurst, T., Ares, A. \& Baruch, Z. (2007) Leaf trait relationships of native and invasive plants: community- and global-scale comparisons. New Phytologist, 176, 635-643.

Lloret, F., Médail, F., Brundu, G., Camarda, I., Moragues, E., Rita, J., Lambdon, P. \& Hulme, P.E. (2005) Species attributes and invasion success by alien plants on Mediterranean islands. Journal of Ecology, 93, 512-520.

Mack, R.N. (2003) Phylogenetic constraint, absent life forms, and preadapted alien plants: a prescription for biological invasions. International Journal of Plant Sciences, 164, S183S196.

Miller, J.P., Murphy, D.J., Brown, G.K., Richardson, D.M. \& González-Orozco, C.E. (2011) The evolution and phylogenetic placement of invasive Australian Acacia species. Diversity and Distributions, 17, 848-860.

Mooney, H.A., Ferrar, P.J. \& Slatyer, R.O. (1978) Photosynthetic capacity and carbon allocation patterns in diverse growth forms of Eucalyptus. Oecologia, 36, 103-111.

Niinemets, Ü. \& Kull, K. (1994) Leaf weight per area and leaf size of 85 Estonian woody species in relation to shade tolerance and light availability. Forest Ecology and Management, 70, 1-10.

Olden, J.D. \& Rooney, T.P. (2006) On defining and quantifying biotic homogenization. Global Ecology and Biogeography Letters, 15, 113-120.

Pyšek, P. \& Richardson, D.M. (2007) Traits associated with invasiveness in alien plants: where do we stand? Biological invasions (ed. by W. Nentwig), pp. 97-125. Springer-Verlag, Berlin Heidelberg. 
Pyšek, P., Sadlo, J., Mandak, B. \& Jarošík, V. (2003) Czech alien flora and the historical pattern of its formation: what came first to Central Europe? Oecologia, 135, 122-130.

Pyšek, P., Richardson, D.M. \& Williamson, M. (2004a) Predicting and explaining plant invasions through analysis of source area floras: some critical considerations. Diversity and Distributions, 10, 179-187.

Pyšek, P., Richardson, D.M., Rejmánek, M., Webster, G., Williamson, M. \& Kirschner, J. (2004b) Alien plants in checklists and floras: towards better communication between taxonomists and ecologists. Taxon, 53, 131-143.

Pyšek, P., Jarošík, V., Pergl, J., Randall, R., Chytrý, M., Kühn, I., Tichý, L., Danihelka, J., Chrtek, J.J. \& Sádlo, J. (2009) The global invasion success of Central European plants is related to distribution characteristics in their native range and species traits. Diversity and Distributions, 15, 891-903.

Rejmánek, M. (1996) A theory of seed plant invasiveness: the first sketch. Biological Conservation, 78, 171-181.

Rejmánek, M. \& Richardson, D.M. (1996) What attributes make some plant species more invasive? Ecology, 77, 16551661.

Richardson, D.M. (2006) Pinus: a model group for unlocking the secrets of alien plant invasions? Preslia, 78, 375-388.

Richardson, D.M. \& Kluge, R.L. (2008) Seed banks of invasive Australian Acacia species in South Africa: Role in invasiveness and options for management. Perspectives in Plant Ecology Evolution and Systematics, 10, 161-177.

Richardson, D.M. \& Pyšek, P. (2006) Plant invasions: merging the concepts of species invasiveness and community invasibility. Progress in Physical Geography, 30, 409-431.

Richardson, D.M. \& Rejmánek, M. (2011) Trees and shrubs as invasive alien species - a global review. Diversity and Distributions, 17, 788-809.

Richardson, D.M., Carruthers, J., Hui, C., Impson, F.A.C., Miller, J.T., Robertson, M.P., Rouget, M., Le Roux, J.J. \& Wilson, J.R.U. (2011) Human-mediated introductions of Australian acacias - a global experiment in biogeography. Diversity and Distributions, 17, 771-787.

Simberloff, D. (2009) We can eliminate invasions or live with them. Successful management projects. Biological Invasions, 11, 149-157.

Thuiller, W., Richardson, D.M., Rouget, M., Procheş, S. \& Wilson, J.R.U. (2006) Interactions between environment, species traits, and human uses describe patterns of plant invasions. Ecology, 87, 1755-1769.

Van Kleunen, M. \& Johnson, S.D. (2007) South African Iridaceae with rapid and profuse seedling emergence are more likely to become naturalized in other regions. Journal of Ecology, 95, 674-681.

Van Kleunen, M., Johnson, S.D. \& Fischer, M. (2007) Predicting naturalization of Southern African Iridaceae in other regions. Journal of Applied Ecology, 44, 594-603.

Van Kleunen, M., Weber, E. \& Fischer, M. (2010) A meta-analysis of trait differences between invasive and noninvasive plant species. Ecology Letters, 13, 235-245.
Vilà, M., Basnou, C., Pyšek, P. et al. (2010) How well do we understand the impacts of alien species on ecosystem services? A pan-European, cross-taxa assessment. Frontiers in Ecology and the Environment, 8, 135-144.

Vitousek, P.M. \& Walker, L.R. (1989) Biological invasion by Myrica faya in Hawai'i: plant demography, nutrient fixation, ecosystem effects. Ecological Monographs, 59, 247-265.

Weber, E. (2003) Invasive species of the world: A reference guide to environmental weeds. CABI Publishing, Oxford, UK.

Werger, M.J.A. \& Ellenbroek, G.A. (1978) Leaf size and leaf consistence of a riverine forest formation along a climatic gradient. Oecologia, 34, 297-308.

Williamson, M. \& Fitter, A. (1996) The characters of successful invaders. Biological Conservation, 78, 163-170.

Wilson, J.R.U., Richardson, D.M., Rouget, M., Procheş, S., Amis, M.A., Henderson, L. \& Thuiller, W. (2007) Residence time and potential range: crucial considerations in modelling plant invasions. Diversity and Distributions, 13, $11-22$.

Wilson, J.R.U., Gairifo, C., Gibson, M.R. et al. (2011) Risk assessment, eradication, and biological control: global efforts to limit Australian acacia invasions. Diversity and Distributions, 17, 1030-1046.

Zheng, Y.L., Feng, Y.L., Liu, W.X. \& Liao, Z.Y. (2009) Growth, biomass allocation, morphology, and photosynthesis of invasive Eupatorium adenophorum and its native congeners grown at four irradiances. Plant Ecology, 203, 263-271.

\section{SUPPORTING INFORMATION}

Additional Supporting Information may be found in the online version of this article:

Appendix S1 Consulted Floras/check lists to determine the invasive status of Acacia species.

Appendix S2 List of ISI Web of Knowledge subjects considered to be applied. The number of these subjects covered by all papers published on each species was the index of human use.

Table S1 Main predictors of Australian Acacia species invasiveness: Human-use index, defined as the number of ISI Web of Knowledge applied subjects covered by all papers published on each species, and Pred1, which accounts for the water availability in the native range.

Table S2 Probability of being invasive calculated for the 85 Acacia species with defined status ( 0 , non-invasive; 1 , invasive), on the basis of Model 1 .

As a service to our authors and readers, this journal provides supporting information supplied by the authors. Such materials are peer-reviewed and may be re-organized for online delivery, but are not copy-edited or typeset. Technical support issues arising from supporting information (other than missing files) should be addressed to the authors. 


\section{BIOSKETCH}

The general research interest of the first author focuses on understanding the mechanisms that allow plant species to be successful in particular habitats. All authors are interested in understanding how and why some introduced species arrive in novel ecosystems, how they negotiate abiotic and biotic filters in the new environment, and what ecological impacts they cause (http://sites.google.com/site/ pilarcastrodiezresearch/home).

Author contributions: P.C.D., O.G. and D.M.R. conceived the ideas; P.C.D., O.G. and A.S. collected the data; P.C.D. and O.G. analysed the data; and P.C.D. led the writing.

Editor: Petr Pyšek 